\title{
Antimicrobial sensitivity and resistance of Salmonella Enteritidis isolated from natural samples
}

\author{
Ramya Putturu, Madhavarao Thirtham and Tirupati Reddy Eevuri
}

College of Veterinary Science,

Sri Venkateswara Veterinary University, Tirupati, Andhrapradesh, India

Corresponding author: Ramya Putturu, email:puttururamya@gmail.com

Received: 04-07-2012, Accepted: 10-08-2012, Published online: 19-01-2013

\section{How to cite this article:}

Putturu R, Thirtham M and Eevuri TR (2013) Antimicrobial sensitivity and resistance of Salmonella Enteritidis isolated from natural samples, Vet. World 6(4): 185-188, doi: 10.5455/vetworld.2013.185-188

\begin{abstract}
Aim: To test the sensitivity of $S$. Enteritidis for selected antibiotics.

Materials and Methods: $S$. Enteritidis isolates obtained from different samples of chicken, mutton, turkey meat, faecal and cloacal samples of poultry and turkey, eggs, water and feed were subjected for sensitivity and resistance to selected antibiotics like- Chloramphenicol $(30 \mu \mathrm{g})$, Gentamicin $(10 \mu \mathrm{g})$, Nalidixic Acid $(30 \mu \mathrm{g})$, Tetracycline $(30 \mu \mathrm{g})$, Ciprofloxacin $(5 \mu \mathrm{g})$, Amikacin $(30 \mu \mathrm{g})$, Amoxicillin $(25 \mu \mathrm{g})$, Ampicillin $(10 \mu \mathrm{g})$, Streptomycin $(10 \mu \mathrm{g})$ and Sulfonamide $(30 \mu \mathrm{g})$. Antimicrobial susceptibility of the isolates was established by the disk diffusion assay with MH (Muller-Hinton) agar in accordance with French National Antibiogram Committee Guidelines.

Results: The sensitivity of $S$. Enteritidis was $100 \%$ for ciprofloxacin followed by chloramphenicol and amikacin (96\%), gentamycin (90\%), amoxicillin (82\%), streptomycin (80\%), tetracycline (76\%), nalidixic acid (68\%), ampicillin (58\%) and sulfonamide (10\%). The resistance was highest for sulfonamide (76\%) followed by ampicillin (32\%), nalidixic acid (30\%) and $6-20 \%$ for gentamycin, amoxicillin and tetracycline.

Conclusion: $S$. Enteritidis isolates were more sensitive to ciprofloxacin, chloramphenicol, amikacin, gentamycin, streptomycin, amoxicillin and tetracyclines and less sensitive to sulfonamides. Higher resistance was observed with sulfonamide followed by ampicillin and nalidixic acid.
\end{abstract}

Keywords : antibiotic resistance, antibiotic sensitivity, $S$. Enteritidis

\section{I ntroduction}

Salmonella food poisoning is one of the most common and widely distributed diseases in the world [1]. Salmonellosis outbreak was linked with wide variety of fruits, vegetables and juices [2]. Prior to 1998 Salmonella Typhimurium was more commonly isolated than $S$. Enteritidis; however in recent years $S$. Enteritidis has been the most common serotype isolated from food and has been particularly responsible for the overall increase in Salmonella infections in humans [3] and is one of the major public health problems in terms of socio-economic impact $[4,5]$. It is estimated that the annual economic cause due to food borne Salmonella infections in the U.S. are $\$ 2.4$ billion [6]. Outbreaks are usually associated with ingestion of contaminated food of animal origin particularly avian products. $S$. Enteritidis has become prevalent in humans and poultry as a result of vertical and horizontal transmission [7].

Although the majority of infections result in asymptomatic or self limited disease in immunocompromised patients, neonates and elderly, antibiotic treatment is usually recommended. Resistance towards the traditional first line antibiotics is multi drug resistance (MDR) in Salmonella enteric [8]. Recently multidrug resistant (MDR) strains have emerged, presumably due to the extensive use of antimicrobial agents both in humans and animals [9]. In veterinary medicine antibiotics are used in livestock production, disease prevention and as growth promoting feed additives [10,11]. Indiscriminate and injudicious use of antibiotics in food animals should be monitored to reduce risk of MDR to humans [12]. Resistant strains of Salmonella to bacitracin, colistin and polymyxin-3 were isolated by Singh et. al., [13] in north India from chicken eggs.

The use of antibiotics disrupts the normal flora of intestine, resulting in emergence of antibiotic resistant strains, which will limit the therapeutic options available for their treatment. The fatality rate for people infected with antibiotic resistant Salmonella strains is 21 times greater than for individuals infected with non antibiotic resistant Salmonella strains [14]. There is a need of continuous surveillance and sharing of antimicrobial susceptibility for Salmonella among countries of worldwide to ensure the effectiveness of control programmes [15].

In the present study we have studied the antimicrobial sensitivity and resistance to certain antibiotics.

\section{Materials and Methods}

A total of 235 samples (randomly collected) of 
Table-1. Antibiotic sensitivity of Salmonella Enteritidis

\begin{tabular}{|c|c|c|c|c|}
\hline \multirow{2}{*}{ Sr. No. } & \multirow[t]{2}{*}{ Antibiotic $(\mu \mathrm{g})$} & \multicolumn{3}{|c|}{ Antimicrobial resistance, No. positive (\%) } \\
\hline & & Sensitive & Intermediate & Resistant \\
\hline 1. & Chloramphenicol $(30 \mu \mathrm{g})$ & $48(96 \%)$ & $2(4 \%)$ & - \\
\hline 2. & Gentamycin $(10 \mu \mathrm{g})$ & $45(90 \%)$ & $2(4 \%)$ & $3(6 \%)$ \\
\hline 3. & Nalidixic Acid $(30 \mu \mathrm{g})$ & $30(60 \%)$ & $5(10)$ & $15(30 \%)$ \\
\hline 4. & Tetracycline $(30 \mu \mathrm{g})$ & $38(76 \%)$ & $2(4 \%)$ & $10(20 \%)$ \\
\hline 5. & Ciprofloxacin $(5 \mu \mathrm{g})$ & $50(100 \%)$ & - & - \\
\hline 6. & Amikacin $(30 \mu \mathrm{g})$ & $48(96 \%)$ & $2(4 \%)$ & - \\
\hline 7. & Amoxicillin $(25 \mu \mathrm{g})$ & $41(82 \%)$ & $1(2 \%)$ & $8(16 \%)$ \\
\hline 8. & Ampicillin $(10 \mu \mathrm{g})$ & $29(58 \%)$ & $5(10 \%)$ & $16(32 \%)$ \\
\hline 9. & Streptomycin $(10 \mu \mathrm{g})$ & $40(80 \%)$ & $5(10 \%)$ & $5(10 \%)$ \\
\hline 10. & Sulfonamide $(300 \mu \mathrm{g})$ & $5(10 \%)$ & $7(14 \%)$ & $38(76 \%)$ \\
\hline
\end{tabular}

chicken (25), turkey meat (20), mutton(25), eggs (25), feed (25), water (25), poultry and turkey faeces ( 25 and 20 respectively), poultry and turkey cloacal samples (25 and 20 respectively) were analyzed for the presence of Salmonella spp. both by cultural and PCR methods. The samples were collected and pre enriched in buffered peptone water, incubated at $37^{\circ} \mathrm{C}$ for $16 \mathrm{~h}$. After pre-enrichment $1 \mathrm{ml}$ of each inoculum was transferred into selective broths (Himedia) including Tetrathionate (TT) broth, Selenite-F (SF) and Selenite cysteine (SC) broths while $0.1 \mathrm{ml}$ to RappaportVassilidias (RV) broth. All broth inoculums were incubated at $42^{\circ} \mathrm{C}$ for $18 \mathrm{~h}$ except SC broth (incubation was at $37^{\circ} \mathrm{C}$ for $18 \mathrm{~h}$ ). All the enriched samples were subjected to PCR confirmation for Salmonella spp. infection using primers specific to invA (invasion A) gene sequence. PCR includes DNA extraction by Boiling and Snap chilling method from the selective broth cultures and then the DNA template was added to PCR reaction mixture and subjected to PCR assay (Initial denaturation, Final denaturation, Annealing, Initial extension, Final extension). The amplified product was tested for the presence of desired gene by using Agarose Gel Electrophoresis. The Salmonella positive samples by PCR method were further characterized for detection of $S$. Enteritidis strains using sefA (Salmonella Enteritidis fimbrial A) gene specific primers (amplification product: $310 \mathrm{bp}$ ).

The invA gene (310bp) and sefA (389bp) genes were targeted for Salmonella and $S$. Enteritidis respectively. Out of 235 samples, 174 samples were positive for Salmonella spp., out of which 126 were positive for $S$. Enteritidis by PCR technique. Fifty isolates of $S$. Enteritidis were subjected for antibiotic sensitivity test, using disk diffusion assay with Muller-Hinton agar in accordance with French National Antibiogram committee guide lines [16]. The antibiotics tested were

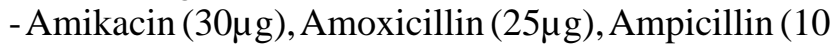
$\mu \mathrm{g})$, Chloramphenicol $(30 \mu \mathrm{g})$, Ciprofloxacin $(5 \mu \mathrm{g})$, Gentamycin $(10 \mu \mathrm{g})$, Nalidixic Acid $(30 \mu \mathrm{g})$, Streptomycin $(10 \mu \mathrm{g})$, Sulfonamide $(300 \mu \mathrm{g})$, Tetracycline $(30$ $\mu \mathrm{g})$.

\section{Results and Discussion}

Antimicrobial resistance of Salmonella has double importance, firstly for the treatment of poultry in which they cause infections and secondly for human infections that they cause disease. One of the main factors for development of antimicrobial resistance is irrational use of antimicrobial drugs. In the present study (Table) $S$. Enteritidis isolates were highly sensitive to ciprofloxacin $(100 \%)$ followed by amikacin $(96 \%)$ and gentamycin (90\%) which were almost similar to the results reported by Ammari et. al. [17], Okamoto et. al. [18] and Nunes et. al., [19]. The resistance of $S$. Enteritidis was zero for ciprofloxacin and amikacin, whereas the resistance to gentamycin was $6 \%$, which are coinciding with the results of Pederson et. al. [20], Turkyilmaz et. al. [21] and Nunes et. al., [19]. Very low level of resistance (0-1\%) to gentamycin was reported by Breuil et. al. [22] and Vaz et. al., [23], whereas Poppe et. al., [24], Aksakal [25] and Aktar et. al., [26] reported higher levels of resistance to gentamycin i.e $25.8 \%, 35 \%$ and $78.57 \%$ respectively.

The sensitivity and resistance of $S$. Enteritidis to chloramphenicol in this study was $96 \%$ and $0 \%$ respectively, which was almost similar to the sensitivity (99\%, $99.6 \%$ and $100 \%$ ) reported by Okamoto et. al. [18], Nunes et. al, [19] \& Aktar, [26] respectively. Very low sensitivity $(2.4 \%)$ and low resistance $(0.4 \%)$ to chloramphenicol was reported by Poppe et. al. [24] and Nunes, [19] respectively. Moderate sensitivity (54.6\%) and resistance $(44.5 \%)$ was reported by Turkyilmaz $e t$. $a l$. [21]. The sensitivity of $S$. Enteritidis to amoxicilin in this study was $82 \%$, whereas the resistance was $16 \%$, which were similar to the results reported by Ammari et. al. [17]. The sensitivity of $S$. Enteritidis to streptomycin in this study was $80 \%$, was almost similar to the sensitivity (83\%) reported by Okamoto, [18] and more than the sensitivity (7.14\%) reported by Aktar et. al., [26]. The resistance to streptomycin was $10 \%$, which was higher than the resistance $(2.08 \% \& 7 \%)$ reported by Vaz, [23]; Okamoto, [18] respectively and less than the resistance $(64.28 \%, 92.85 \%)$ reported by Sultana, [27], Aktar, [26]. The sensitivity of $S$. Enteritidis to tetracycline in this study was $76 \%$, was almost similar to the sensitivity (78\%) reported by Okamoto et. al. [18] and more than the sensitivity (13.7\% and 64.28\%) reported by Nunes, [19] and Aktar, [26]. The resistance to tetracycline was $20 \%$, which was higher than the resistance ( $8.7 \%$ ) reported by Pederson et. al. [20], and less than the resistance (35-38\%) reported by Aksakal [25] and Poppe et. al. [24]. Very low level of resistance was reported by Vaz, [23] (1.04\%) and Nunes, [19] $(2.1 \%)$. The resistance to tetracycline might be due to this antibiotic being one of the most commonly used 
antibiotics for animal production.

The sensitivity of $S$. Enteritidis to nalidixic acid in the present study was $60 \%$, which was much higher than the sensitivity (18\% \& 27\%) reported by Okamoto et. al. [18] \& Nunes, [19] respectively, and lower than the sensitivity $(93.33 \%$ and $97.9 \%)$ reported by Ammari et. al. [17] and Nunes, [19]. The resistance to nalidixic acid (30\%) in the present study was similar to the resistance reported by Cruchaga and Ecifita, [28], whereas low resistance of $(1-4 \%)$ was observed by Breuil et. al. [22] \& Nunes et. al., [19]. High resistance than the present study was reported by Fasche, [29] $(81 \%)$ and Kottwitz, [30] (41.5\%). The sensitivity of $S$. Enteritidis to ampicillin in the present study was 58\%, which was similar to the results reported by Okamoto et. al. [18] and Turkyilmaz et. al. [21] and less than the sensitivity $(86.66 \%, 97.8 \%$ \& $92.85 \%)$ reported by Ammari et. al. [17], Nunes, [19] \& Aktar, [26]. The resistance to ampicillin was $32 \%$ which was higher than the resistance $(2.1 \%, 12.1 \%, 14.3 \%$ and $25 \%)$ reported by Aksakal [25] and Poppe et. al. [24] Nunes, [19] and Makaya, [31] respectively and less than the resistance $(41 \%)$ reported by Okamoto et. al. [18]. Poor sensitivity (10\%) and higher resistance (76\%) to sulfonamide were observed in the present study were similar to the results reported by Nogueria et. al. [32] and Okamoto et. al. [18] Nunes, [19]. Very poor resistance of $S$. Enteritidis to sulfonamides $(1.7 \%)$ was reported by Poppe et. al. [24] and Pederson et. al. [20], whereas $20 \%$ resistance was reported by Aksakal [25], and $34.37 \%$ by Vaz et. al., [23]. Very high resistance was reported by Carraminana et. al., [33] (99\%), and Cardoso et. al., [34] (86.25\%).

Indiscriminate use of antibiotics results in varied degrees of antibiotic resistance, which will increase the course of any infectious disease. The other antibiotics which were not studied in this study may be carried out in future.

\section{Conclusion}

$S$. Enteritidis isolates were more sensitive to ciprofloxacin, chloramphenicol, amikacin, gentamycin, streptomycin, amoxicillin and tetracyclines and less sensitive to sulfonamides. Higher resistance was observed with sulfonamide followed by ampicillin and nalidixic acid.

\section{Author's contribution}

MT had planned the study, helped in analysis and drafted the manuscript. RP analysed the results and had written the revised the manuscript, TRE collected the samples, and analysed the data. All the authors read and approved the final manuscript.

\section{Acknowledgements}

We are very thankful to Sri Venkateswara Veterinary University for providing necessary infrastructure and facilities for conducting this work.

\section{Competing interests}

Authors declare that they have no competing interests.

\section{References}

1. Gomez, T.M., Motarjemi, Y., Miyagawa, S., Kaferstein, F.K. and Stohr, K. (1997) Food borne salmonellosis. World Health Stat Q., 50:81-9.

2. Pui, C. F., Wong, W. C., Chai, L. C., Lee, H. Y., Tang, J.Y. H., Noorlis, A., Farinazleen, M. G., Cheah, Y. K. and Son, R. (2011) Biofilm formation by Salmonella Typhi and Salmonella Typhimurium on plastic cutting board and its transfer to dragon fruit. International Food Research Journal., 18:31-38.

3. Hilton, A.C. and Penn, C. (1998) Restriction enzyme analysis of randomly amplified polymorphic DNA amplicons of Salmonella enteric ser. Enteritidis PT4 and Typhimurium DT104. J Microbiol., 27:158-162.

4. Mushtaq-ul-Hassan, Hussain, M.I., Shahzadi, B., Shaheen, M., Mahmood, M.S., Rafique, A. and Mahmood-ul- Hassan, M. (2008) Occurrence of some zoonotic microorganisms in faecal matter of house rat (Rattus rattus) and house mouse (Mus musculus) trapped from various structures. Pakistan Vet. J., 28(4): 171-174.

5. Razzaque, M.A., Bedair, M., Abbas, S. and Al-Mutawa, T. (2009) Economic impact of calf mortality on dairy farms in Kuwait. Pakistan Vet. J., 29(3): 97-101.

6. Gebreyes, W.A. and Altier, C. (2002) Molecular characterization of Multidrug-Resistant Salmonella enteric subsp. Enteric serovar Typhimurium isolates from swine. $J$ Clin Microbiol., 40:2813-2822.

7. O'Brien, J.P.D. (1990) Aspects of Salmonella Enteritidis control in poultry. World's Poultry Sci., 46:119-124.

8. Crump, J. A. and Mintz, E. D. (2010) Global trends in typhoid and paratyphoid fever. Emerging Infections., 50: 241-246.

9. Miriagou, V., Carattoli, A. and Fanning, S. (2006) Antimicrobial resistance islands: resistance gene clusters in Salmonella chromosome and plasmids. Microbes Infect., 8:1923-1930.

10. Van, T.T.H., Moutafis, G., Istivan, T., Tran, L.T. and Coloe, P.J. (2007) Detection of Salmonella spp. in retail raw food samples from Vietnam and characterization of their antibiotic resistance. Appl Environ Microbiol., 73:6885-6890.

11. Yang, B., Qu, D., Zhang, X., Shen, J., Cui, S., Shi, Y., Xi, M., Sheng, M., Zhi, S. and Meng, J. (2010) Prevalence and characterization of Salmonella serovars in retail meats of marketplace in Shaanxi, China. International Journal of Food Microbiology., 141(1-2): 63-72.

12. Zhao, S., Datta, A. R., Ayers, S., Friedman, S., Walker, R. D. and White, D. G. (2003) Antimicrobial-resistant Salmonella serovars isolated from imported foods. International Journal of Food Microbiology., 84(1): 87-92.

13. Singh, S., Yadav, A. S., Singh, S. M. and Bharti, P. (2010) Prevalence of Salmonella in chicken eggs collected from poultry farms and marketing channels and their antimicrobial resistance. Food Research International., 43(8): 2027-2030.

14. Helms, M., Vastrup, P., Gerner-Smidt. and Molbak, L. (2003) Short and long term mortality associated with foodborne bacterial gastrointestinal infections: registry based study. BMJ., 326-357.

15. de Oliveira, F. A., Pasqualotto, A. P., da Silva, W. P. and Tondo, E. C. (2010) Characterization of Salmonella Enteritidis isolated from human samples. Food Research International, In Press, Corrected Proof. doi:10.1016/j. foodres.2010.09.040.

16. Bessa, M.C., Michael, G.B., Canu, N., Canal, C.W., Cardoso, M., Rabsch, W. and Rubino, S. (2007) Phenotypic and genetic characterization of Salmonella enteric subsp. Enterica serovar Typhimurium isolated from pigs in Rio Grande do Sul Brazil. Research in Veterinary Science., 83:302-310.

17. Ammari, S., Laglaoui, A., En-nanei, L., Bertrand, S., Wildemauwe, C., Barrijal, S. and Abid, M. (2009) Characterization of Salmonella Enteritidis isolated from 
foods and patients in northern Morocco. $J$ Infect Dev Ctries.,3(9):695-703.

18. Okamoto, A.S., AndreattiFilho, R.L., Rocha, T.S., Menconi, A. and Marrietto-Goncalves, G.A. (2009) Detection and transfer of antimicrobial resistance gene integron in Salmonella Enteritidis derived from avian material. Brazilian J Poultry Sci., 11:195-201.

19. Nunes, I.A., Osugui, Silvia K., Andrade, M.A., Rivera, I.N.G., Rauecker, U.N. and Ferreira, A.J.P. (2009) Antimicrobial susceptibility of Salmonella Enteritidis strains from different sources. Ciência Animal Brasileira., 10(1): 166-173.

20. Pederson, K., Hansen, H.C., Jorgensen, J.C. and Borck, B. (2002) Serovars of Salmonella isolated from Danish turkeys between 1995 and 2000 and their antibiotic resistance. Vet Rec., 150:471-474.

21. Turkyilmaz, S., Hazimoglu, S. and Bozdogan, B. (2009) Antimicrobial susceptibility and resistance genes in Salmonella enteric serovar Enteritidis isolated from turkeys. Israel J Vet Med., 64(3).

22. Breuil, J., Brisabois, A., Casin, I., Armand, L., Frémy, S. and Collatz, E. (2000) Antibiotic resistance in Salmonellae isolated from humans and animals in France: comparative data from 1994 and 1997. Journal of Antimicrobial Chemotherapy., 46:965-971.

23. Vaz, C. S. L., Streck, A. F., Michael, G. B., Marks, F. S., Rodrigues, D. P., dos Reis, E. M. F., Cardoso, M. R. I. and Canal, C. W. (2010) Antimicrobial resistance and subtyping of Salmonella enterica subspecies enterica serovar Enteritidis isolated from human outbreaks and poultry in southern Brazil. Poultry Science., 89: 1530-1536.

24. Poppe, C., Kolar, J.J., Demckzuk, W.H.B. and Harris, J.E. (1995) Drug resistance and biochemical charecteristics of Salmonellae from turkeys. Can J Vet Res., 59:241-248.

25. Aksakal, A. (2003) The occurrence and prevalence Salmonella species in faeces of certain fowls and their susceptibility to antibiotics (In Turkish). YYU Vet Fak Derg., 14:95-101.
26. Akhtar, F., Hussain, I., Khan, A. and Rahman, S. U. (2010) Prevalence and Antibiogram Studies of Salmonella Enteritidis Isolated from Human and Poultry Sources. Pakistan Vet. J., 30(1): 25-28.

27. Sultana, K., Bushra, M.A. and Nafisa, I. (1995) Evaluation of antibiotic resistance in clinical isolates of $S$. Typhi from Islamabad, Pakistan. Zoology., 27(2): 185-187.

28. Cruchaga, S. and Echfita, M. (2001) Antimicrobial resistance in Salmonellae from humans, food and animals in Spain in 1998. Journal of Antimicrobial Chemotherapy., 47:315-321.

29. Fashae, K., Folasade, O., Frank, M., Aarestrup, R. and Hendriksen, S. (2010) Antimicrobial susceptibility and serovars of Salmonella from chickens and humans in Ibadan, Nigeria. J Infect Dev Ctries., 4(8): 484-494.

30. Kottwitz, L.B.M., Scheffer, M.C., Dalla-Costa, L.M., Farah, S.M.S. S., Moscalewski, W.S.B., Magnani, M. and de Oliveira, T.R.C.M. (2011) Molecular characterization and resistance profile of Salmonella Enteritidis PT4 and PT9 strains isolated in Brazil. J Med Microbiol., 60(7):10261031.

31. Makaya, P. V., Matope, G. and Pfukenyi, D. M. (2012) Distribution of Salmonella serovars and antimicrobial susceptibility of Salmonella Enteritidis from poultry in Zimbabwe. Avian Pathology. 41: 221-226.

32. Nogueria, I.A., Brasil, P., Conceicao, M. and Martins, I.S. Recomendacoes para o uso adequado dos antimicrobianos (citado em 2006. Dez 16). Disponivel em: http://www. saude. rj. gov.br/cecih/Antimicrobianos.doc. retrieved on 12-06-2012.

33. Carramiñana, J. J., Rota, C., Agustín, I. and Herrera. A. (2004) High prevalence of multiple resistance to antibiotics in Salmonella serovars isolated from a poultry slaughter house in Spain. Vet. Microbiol., 104: 133-139.

34. Cardoso, M.O., Ribeiro, A.R., dos Santos, L.R., Pilotto, F., de Moraes, H.L.S., Salle, C.T.P., da Silveira Rocha, S . L . and do Nascimento, V.P. (2006) Antibiotic resistance in Salmonella Enteritidis isolated from broiler carcasses. Brazilian Journal of Microbiology., 37: 368-371. 